\author{
К. В. Базіло, к.т.н., дочент \\ Черкаський державний технологічний університет \\ б-р Шевченка, 460, Черкаси, 18006, Україна
}

\title{
ДОСЛІДЖЕННЯ ЕЛЕКТРИЧНОГО ІМПЕДАНСУ П'ЄЗОЕЛЕКТРИЧНОГО ДИСКА З СЕКТОРНИМИ ЕЛЕКТРОДАМИ
}

В наш час провідні виробники радіоелектронних компонентів випускають досить великий перелік елементів, до складу яких включені різні мікроелектромеханічні структури, наприклад, різні акселерометри, резонатори і реалізовані на їх основі фільтри електричних сигналів, трансформатори та інші мікромініатюрні електромеханічні системи.

П'єзоелектричні диски з секторним електродуванням поверхні є практично основним елементом багатьох мікроелектромеханічних систем.

Основною метою статті $\epsilon$ дослідження електричного імпедансу дискових n'єзокерамічних трансформаторів з розрізними електродами.

Ключові слова: n'єзоелектричний трансформатор, фізичні прочеси, електричний імпеданс, секторні електроди.

Вступ. В наш час провідні виробники радіоелектронних компонентів випускають досить великий перелік елементів, до складу яких включені різні мікроелектромеханічні структури (МЕМС), наприклад, різні акселерометри, резонатори і реалізовані на їх основі фільтри електричних сигналів, трансформатори та інші мікромініатюрні електромеханічні системи [1].

П'єзоелектричні диски з частковим електродуванням однієї або двох поверхонь досить часто використовуються для створення різних функціональних пристроїв п'єзоелектроніки [2]. Диски з секторним електродуванням поверхні $є$ практично основним елементом багатьох мікроелектромеханічних систем [1].

Відмінною рисою між МЕМС і звичайними п'єзоелементами $є$ спосіб електродування робочих поверхонь. У МЕМС, як правило, використовується часткове електродування робочих поверхонь, коли тільки частина поверхні поляризованого сегнетоелектрика покривається металевою плівкою. Цей спосіб електродування дозволяє порушувати в об'ємі MEMC кілька типів пружних коливань [3].

В тонких п'єзоелектричних дисках з розрізними електродами виникають невісесиметричні пружні коливання. Теоретичні та експериментальні дослідження кінематичних характеристик невісесиметричних планарних коливань в п'єзоелектричних тонких дисках взагалі і в дисках з частковим електродуванням однієї або двох поверхонь зокрема почалися в другій половині XX ст. Результати цих робіт певною мірою узагальнені в монографії [4]. Нині продовжують публікуватися роботи [5--7], в яких розглядаються різні аспекти теорії невісесиметричних планарних коливань в тонких п'єзоелектричних дисках.

Основною метою статті $є$ дослідження електричного імпедансу дискових п'єзокерамічних трансформаторів 3 розрізними електродами.

\section{1. Дослідження п'єзоелектричного ди-} ска з секторними електродами

Будемо вважати, що п'єзоелектричний диск не має механічних контактів 3 іншими матеріальними об'єктами, тобто утримується в просторі гнучкими і невагомими нитками. Це дозволяє говорити, що диск не відчуває реакції з боку навколишнього середовища, тобто фактично знаходиться у вакуумі.

Нижня поверхня диска $\mathrm{z}=0$ ( $\mathrm{z} \quad$ координатна лінія циліндричної системи координат ( $\rho, \varphi, z)$, сполучена з віссю $x_{3}$ правогвинтової декартової системи координат $\left(\mathrm{x}_{1}, \mathrm{x}_{2}, \mathrm{x}_{3}\right)$ (рис. 1)) покрита тонким шаром металу і заземлена, тобто в будь-який момент часу її електричний потенціал дорівнює нулю. Верхня поверхня $\mathbf{z}=\alpha$ диска покривається двома секторними електродами (позиції 1 і 2 на рис. 1). Секторні електроди 1 і 2 розділяє неелектродований зазор, ширина якого істотно менша товщини $\alpha$ п'єзокерамічного диска, причому $\alpha / R<1$, де $R$ - радіус диска. Половинний кут розкриття секторного електрода в первинному електричному колі 
п’єзокерамічного трансформатора позначений символом $\vartheta_{0}$.

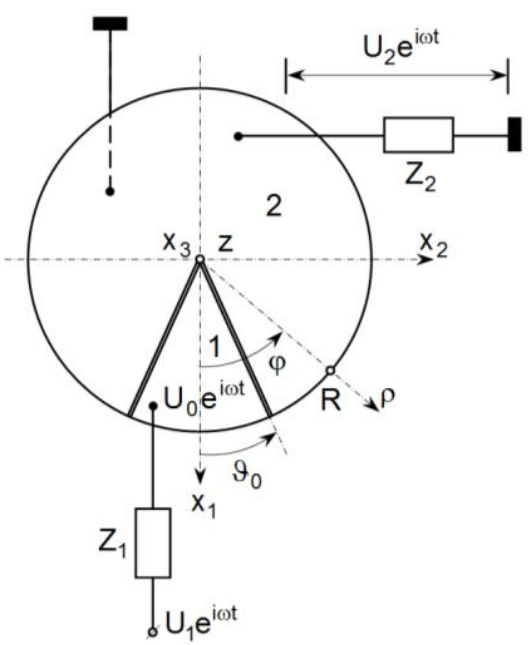

Рис. 1. Схема об'єкта

На секторний електрод 1 подається гармонійно змінна в часі різниця електричних потенціалів $\mathrm{U}_{0} \mathrm{e}^{\mathrm{i} \omega \mathrm{t}}\left(\mathrm{U}_{0}-\right.$ амплітуда різниці електричних потенціалів на електроді 1 ; $\mathrm{i}=\sqrt{-1}-$ уявна одиниця; $\omega-$ кругова частота зміни знаку електричного потенціалу; $\mathrm{t}$ час). Символом $Z_{1}$ позначено комплексний вихідний опір джерела електричного сигналу; $\mathrm{U}_{1}$ - амплітудне значення різниці потенціалів на виході джерела електричних сигналів; $Z_{э л}^{(1)}(\omega)$ - електричний імпеданс елемента п'єзокерамічного диска під секторним електродом 1. Електричний потенціал формує під електродом 1 змінне електричне поле, яке породжує в об'ємі п'єзокерамічного диска гармонійно змінні в часі пружні деформації. Внаслідок прямого п'єзоелектричного ефекту гармонійні коливання матеріальних частинок диска генерують на секторному електроді 2 поляризаційний заряд $\mathrm{q}_{2}(\mathrm{t})=\mathrm{Q}_{2} \mathrm{e}^{\mathrm{i} \omega \mathrm{t}}$, де $\mathrm{Q}_{2}-$ амплітудне значення поляризаційного заряду. Поляризаційний заряд $\mathrm{q}_{2}(\mathrm{t})$ своїм електричним полем переміщує вільні носії електрики (електрони) в провіднику електричного струму, який з'єднує електричне навантаження $Z_{2}$ 3 секторним електродом 2. При проходженні електричного струму через комплексний опір $\mathrm{Z}_{2}$ на ньому виділяється різниця потенціалів $\mathrm{U}_{2} \mathrm{e}^{\mathrm{i} \omega \mathrm{t}}$, де $\mathrm{U}_{2}$ - амплітудне значення різниці потенціалів у вторинному електричному колі п'єзоелектричного трансформатора.
Оскільки джерело електричного потенціалу в первинному електричному колі трансформатора має відмінний від нуля комплексний вихідний опір $Z_{1}$, то амплітудне значення $\mathrm{U}_{0}$ електричного потенціалу на секторному електроді 1 відрізнятиметься (природно, в меншу сторону) від амплітудного значення $\mathrm{U}_{1}$.

В роботі [8] наведені розрахунки нульового наближення до точного значення частотного рівняння невісесиметричної, номера $\mathrm{m}$, моди планарних коливань тонкого п'єзокерамічного диска $\Psi_{0}^{(\mathrm{m})}(\gamma, \lambda, \mathrm{R})$, причому $\gamma=\omega / \sqrt{c_{11}^{*} / \rho_{0}}-$ хвильове число радіальних коливань тонкого диска; $\lambda=\omega / \sqrt{\left(c_{11}^{*}-c_{12}^{*}\right) /\left(2 \rho_{0}\right)}-$ хвильове число окружних планарних коливань матеріальних частинок тонкого п'єзокерамічного диска, де $\rho_{0}$ - густина п'єзокераміки; с $c_{11}^{*}$ - модуль пружності тонкого п'єзокерамічного диска для режиму планарних коливань; $c_{12}^{*}=c_{12}^{E}\left(1-c_{12}^{E} / c_{33}^{E}\right) ; \quad c_{12}^{E}$ i $c_{33}^{E}-$ довідкові значення модулів пружності для поляризованої по товщині диска п'єзокераміки.

Числові значення коренів $\chi_{n}^{(\mathrm{m})}=\gamma_{n}^{(\mathrm{m})} R$ $(n=1,2,3, \ldots)$ рівняння $\Psi_{0}^{(m)}\left(\gamma_{n}, \lambda_{n}, R\right)=0$ для окружних гармонік з номерами $\mathrm{m} \geq 1$ в діапазоні значень безрозмірних хвильових чисел (частот) $\gamma R \leq 10$ для параметра пружних властивостей п'єзокераміки $\mathrm{k}=\mathrm{c}_{12}^{*} / \mathrm{c}_{11}^{*}=0,34$ для невісесиметричних планарних коливань круглого диска, які можуть у ньому виникати через секторне електродування, показані в табл. 1.

Слід звернути увагу на те, що перший корінь $\chi_{1}^{(1)}$ або, що те саме, частота першого електромеханічного резонансу для першої $(m=1)$ окружної моди, має менше значення порівняно з частотою першого електромеханічного резонансу вісесиметричних радіальних коливань. Зі зростанням номера $\mathrm{m}$ окружної моди числові значення безрозмірної частоти $\gamma_{1}^{(m)} \mathrm{R}$ монотонно зростають, $\mathrm{i}$ тому загальне число коренів рівняння $\Psi_{0}^{(\mathrm{m})}\left(\gamma_{n}, \lambda_{n}, R\right)=0$ в будь-якому фіксованому діапазоні числових значень безрозмірних хвильових чисел (частот) має фіксоване (обмежене) значення. 
Числові значення коренів рівняння $\Psi_{0}^{(\mathrm{m})}\left(\gamma_{n}, \lambda_{n}, \mathrm{R}\right)=0$

\begin{tabular}{|c|c|c|c|c|c|c|}
\hline $\mathrm{m} \backslash \chi_{n}^{(\mathrm{m})}$ & $\chi_{1}^{(\mathrm{m})}$ & $\chi_{2}^{(\mathrm{m})}$ & $\chi_{3}^{(\mathrm{m})}$ & $\chi_{4}^{(\mathrm{m})}$ & $\chi_{5}^{(\mathrm{m})}$ & $\chi_{6}^{(\mathrm{m})}$ \\
\hline 1 & 1,085045 & 2,464587 & 3,674256 & 7,571771 & 8,735141 & 9,413737 \\
\hline 2 & 2,057536 & 3,134450 & 4,846928 & 6,378587 & 6,729860 & - \\
\hline 3 & 2,966933 & 3,690970 & 6,101373 & 6,889025 & 8,130622 & - \\
\hline 4 & 3,819653 & 4,700591 & 9,486512 & - & - & - \\
\hline 5 & 4,618638 & 5,552675 & - & - & - & - \\
\hline 6 & 5,374142 & 6,435415 & - & - & - & - \\
\hline 7 & 6,098880 & 7,336232 & - & - & - & - \\
\hline 8 & 6,802725 & 8,245702 & - & - & - & - \\
\hline 9 & 7,492040 & 9,157764 & - & - & - & - \\
\hline 10 & 8,170770 & - & - & - & - & - \\
\hline 11 & 8,841415 & - & - & - & - & - \\
\hline 12 & 9,505634 & - & - & - & - & - \\
\hline
\end{tabular}

Примітка: прочерк у коміричі означає, що числове значення кореня більще 10.

В роботі [9] розглянуто методику експериментального визначення електричного імпедансу п'єзокерамічного диска. Схема для проведення експериментальних досліджень наведена на рис. 2.

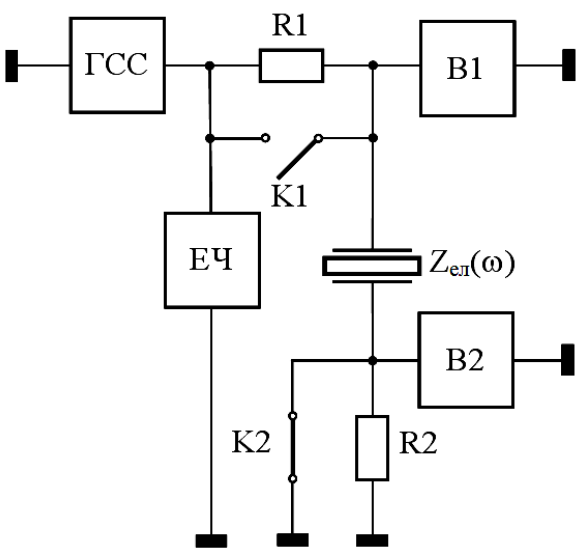

Рис. 2. Електрична схема для вимірювання електричного імпедансу п'єзокерамічного диска

Для виконання експериментальних досліджень використовувалися масивні диски. При цьому мінімізуються ефекти, пов'язані з приєднаною масою, яка виникає в процесі пайки провідників до електродованих поверхонь диска.

При вимірюванні електричного імпедансу $\mathrm{Z}_{\text {å̈ }}(\omega)$ диск підвішувався в повітрі на тонких нитках для того, щоб уникнути механічного контакту з іншими об'єктами.
На схемі (рис. 2) абревіатурою ГСС позначений генератор синусоїдальних сигналів, ЕЧ - електронний частотомір, В1 і В2 - електронні вольтметри, К1 і К2 - ключі, що механічно замикаються й розмикаються, R1 i R2 навантажувальні резистори. Символом $\mathrm{Z}_{\text {aё }}(\omega)$ на рис. 2 позначений досліджуваний зразок. Показане на схемі положення ключів К1 і К2 відповідає режиму вимірювання електричного імпедансу в околиці частоти електромеханічного резонансу. Навантажувальні резистори R1 i R2 підбираються таким чином, щоб вольтметри В1 і В2 працювали в діапазоні своєї максимальної чутливості, тобто на шкалах $(1 \div 10)$ мB . Величини резисторів R1 i R2 повинні бути визначені 3 точністю до одного Ома.

Для експериментальних досліджень був використаний дисковий п'єзоелектричний елемент Ø66×3 мм з матеріалу типу ЦТС.

Результати вимірювання електричного імпедансу п'єзоелектричного диска при різних значеннях кута розкриву секторного електрода в первинному електричному колі представлені на рис. 3.

3 експерименту випливає, що в міру зменшення кута розкриву сектора у формуванні напружено-деформованого стану диска починають приймати все більше число невісесиметричних мод, i число резонансів після першого вісесиметричного радіального резонансу зростає. 


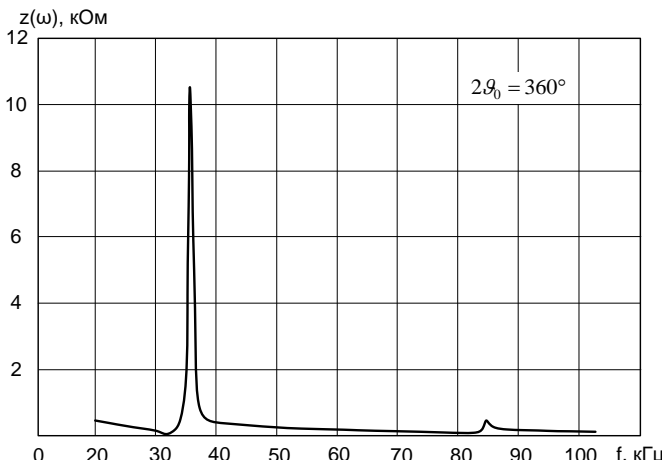

a)

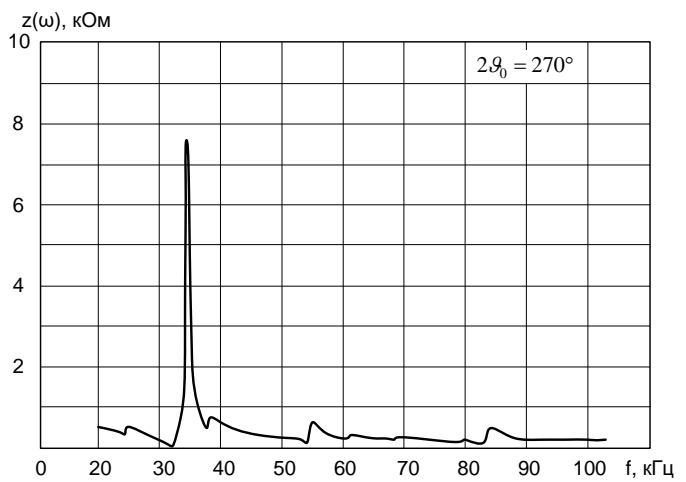

б)

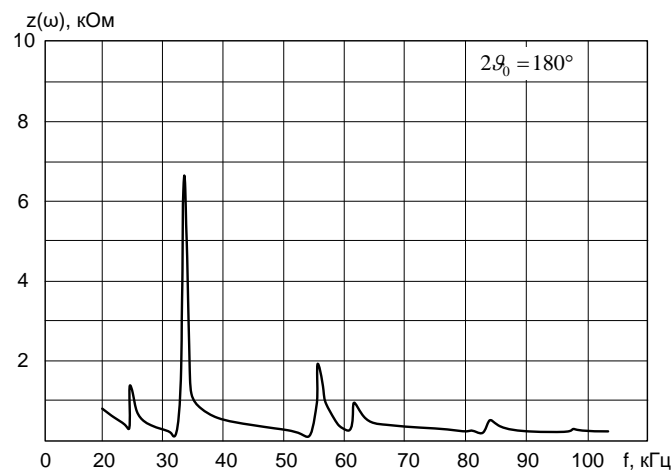

в)

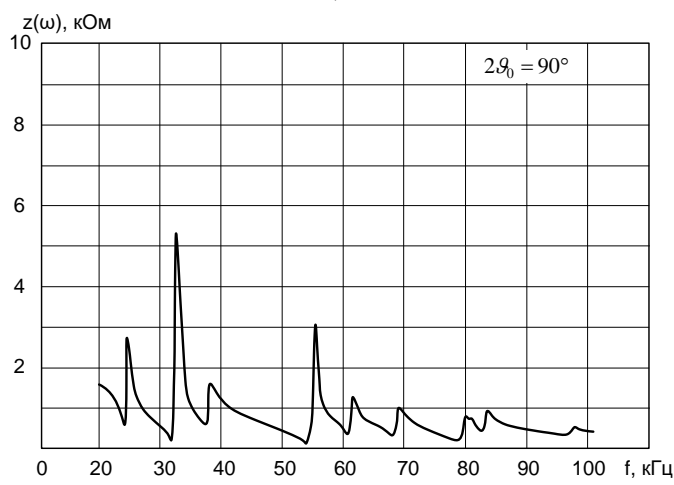

2)

Рис. 3. Електричний імпеданс п'єзоелектричного диска при різних значеннях кута розкриву секторного електрода в первинному електричному колі: a) $2 \vartheta_{0}=360^{\circ}$; б) $2 \vartheta_{0}=270^{\circ}$;

$$
\text { в) } 2 \vartheta_{0}=180^{\circ} \text {; г) } 2 \vartheta_{0}=90^{\circ}
$$

Висновки. Основний результат цієї статті можна зафіксувати наступним чином:

- частота першого електромеханічного резонансу для першої окружної моди має менше значення порівняно $з$ частотою першого електромеханічного резонансу вісесиметричних радіальних коливань;

- в міру зменшення кута розкриву сектора у формуванні напружено-деформованого стану диска починають приймати все більше число невісесиметричних мод, і число резонансів після першого вісесиметричного радіального резонансу зростає.

\section{Список літератури}

1. Варадан В., Виной К., Джозе К. ВЧ МЭМС и их применение. Москва: Техносфера, 2004. $528 \mathrm{c}$.

2. Джагупов Р. Г., Ерофеев А. А. Пьезоэлектронные устройства вычислительной техники, систем контроля и управления. СПб.: Политехника, 1994. 608 с.

3. Petrishchev O. N., Bazilo C. V. et al. (2014). Principles of calculation of piezoelectric elements with surfaces partial covering by electrodes. Вісник Черкаського державного технологічного університету. Серія: Технічні науки. № 3. С. 47-55.

4. Шульга М. О., Карлаш В. Л. Резонансні електромеханічні коливання п'єзоелектричних пластин. Київ: Наук. думка, 2008. 272 c.

5. Naciri I., Elmaimouni L., Lefebvre J.-E., Rguiti M., Ratolojanahary F. E., Gryba T. Modeling of MEMS resonator piezo-electric disc partially covered with electrodes. American Journal of Mechanics and Applications. 2016. Vol. 4, No. 1. P. 1-9.

6. Staworko M., Uhl T. (2008). Modeling and simulation of piezoelectric elements - comparison of available methods. Mechanics, Vol. 27, No. 4. P. 161-171.

7. Leinonen M., Palosaari J., Juuti J., Jantunen H. (2014). Combined electrical and electromechanical simulations of a piezoelectric Cymbal harvester for energy harvesting from walking. Journal of Intelligent Material Systems and Structures. 2014. 25 (4). P. 391-400.

8. Петрищев О. Н., Базило К. В. Расчет коэффициента трансформации пьезокерамического трансформатора с секторными электродами. Вісник Черкаського державного 
технологічного університету. Серія: Технічні науки. 2017. № 4. С. 63-69.

9. Петрищев О. Н., Базило К. В. Методика определения физико-механических параметров пьезоэлектрической керамики. Журнал нано- та електронної фізики. Суми, 2017. Т. 9. № 3.

\section{References}

1. Varadan, V., Vinoy, K. and Jose, K. (2004) RF MEMS and their applications. Moscow: Texnosfera, 528 p. [in Russian].

2. Dzhagupov, R. G. and Erofeev, A. A. (1994) Piezoelectronic device of computing, control and monitoring systems. St. Petersburg: Politehnika, 608 p. [in Russian]

3. Petrishchev, O. N., Bazilo, C. V. et al. (2014) Principles of calculation of piezoelectric elements with surfaces partial covering by electrodes. Visnyk Cherkaskogo derzhavnogo tehnologichnogo universitetu. Seria: Tehnichni nauky, No. 3, pp. 47-55.

4. Shulga, M. O., Karlash, V. L. (2008) Resonant electromechanical oscillations of piezoelectric plates. Kyiv: Nauk.dumka, 272 p. [in Ukrainian].
5. Naciri, I., Elmaimouni, L., Lefebvre, J.-E., Rguiti, M., Ratolojanahary, F. E. and Gryba, T. (2016) Modeling of MEMS resonator piezoelectric disc partially covered with electrodes. American Journal of Mechanics and Applications, Vol. 4, No. 1, pp. 1-9.

6. Staworko, M. and Uhl, T. (2008) Modeling and simulation of piezoelectric elements comparison of available methods. Mechanics, Vol. 27, No. 4, pp. 161-171.

7. Leinonen, M., Palosaari, J., Juuti, J. and Jantunen, H. (2014) Combined electrical and electromechanical simulations of a piezoelectric Cymbal harvester for energy harvesting from walking. Journal of Intelligent Material Systems and Structures, 25 (4), pp. 391-400.

8. Petrishchev, O. N. and Bazilo, C. V. (2017) Calculation of transformation coefficient of piezoceramic transformer with sector electrodes. Visnyk Cherkaskogo derzhavnogo tehnologichnogo universitetu. Seria: Tehnichni nauky, No. 4, pp. 63-69 [in Russian].

9. Petrishchev, O. N. and Bazilo, C. V. (2017). Methodology of determination of physical and mechanical parameters of piezoelectric ceramics. Journal of Nano- and Electronic Physics, Vol. 9, No. 3 [in Russian].

C. V. Bazilo, Ph.D. (Eng.), associate professor

Cherkasy State Technological University

Shevchenko blvd, 460, Cherkasy, 18006, Ukraine

\section{RESEARCH OF ELECTRICAL IMPEDANCE OF PIEZOELECTRIC DISK WITH SECTOR ELECTRODES}

Currently leading manufacturers of electronic components serially produce a rather extensive list of elements, in which various microelectromechanical structures, such as various accelerometers, resonators and electrical signals filters implemented on their basis, transformers and other microminiature electromechanical systems, are included.

Piezoelectric disks with partial covering by electrodes of one or two surfaces are often used to create various functional piezoelectronic devices. Disks with sector covering by electrodes are almost the main element of many microelectromechanical systems.

The purpose of this article is to research electrical impedance of disk piezoceramic transformers with sector electrodes.

Key words: piezoelectric transformer, physical processes, electrical impedance, sector electrodes.

Стаття надійшла 06.03.2018.

Рецензенти: $\quad$ В. В. Палагін, д.т.н., професор,

B. I. Гордієнко, д.т.н., с.н.с. 